\title{
3 types of vehicle-bridge coupling vibration analysis of model
}

\author{
comparison \\ ${ }^{\mathrm{a} C h e n ~ x u-y o n g, ~}{ }^{\mathrm{b}}$ Song teng-teng, ${ }^{\mathrm{C}}$ Luo lu \\ aWuan Institute of Technology, Wuhan, China \\ buhan Institute of Technology, Wuhan, China \\ cWuhan Institute of Technology, Wuhan, China
}

Key words: Vehicle-bridge coupling vibration;Vehicle model;Vibration

Abstract: Compares two 1/4 car models, two 1/4 model (changes the spring stiffness) and 1/2 car models three vehicles at the same speed in the displacement effect. Comparison: when the vehicle speed is less than $130 \mathrm{~km} / \mathrm{h}$, and displacement response curves in the three models are calculated when a highway bridge coupling vibration analysis of vehicle is two one-fourth model can be used to simulate.

\section{Introduction}

Vehicle-bridge coupled vibration attracts many researchers' attention as early as 100 years ago. The current study has simplified the vehicle and bridge model in it to make for a simpler solution.

In recent years, many Chinese researchers are trying to use numerical method to solve coupling problems. The document ${ }^{[4]}$ builds overall 3D model to make the interaction between vehicle and bridge as a whole, thus establishing differential equations, with the kelp of numerical methods, the dynamic response is obtained with respect to simple-supported girder and continuous beam in highway. The document ${ }^{[5-6]}$ makes a model of vehicle bridge coupling of simple-supported beam bridge employing d'alembert's principle and uses numerical methods to solve the problem. Step-by-step integral is used to calculate the coupling system consisting of mass with uniform variable speed and a simple supported beam. The document ${ }^{[8]}$ acquires the power series solution to Willis equation. The document ${ }^{[9]}$ derives the vibration equation by ignoring moving constant loads of mass vehicle and thus gets the exact solution. The document ${ }^{[10]}$ uses concentrated mass as the simplified bridge model and adds 2D multi-axis trailer load.

To investigate the influence of vehicle model on vehicle-bridge coupling, three kinds of models:two quarter-car models(spring stiffness changed) and half-car models with different velocity, are used to analyze displacement response. The overall laws are analyze in the first place which followed the analysis of difference of models.

\section{Model \\ one-fourth car models}

Figure 1 is vehicle model, the spring-damper-mass system is for simulating vehicles. Where $m_{b}$ is vehicle mass. $m_{t}$ is the frame and wheel mass; $k_{a}$ is vertical stiffness; $c_{a}$ is vertical damping; $k_{b}$ is vertical stiffness; $c_{b}$ is vertical damping; $v$ is the speed when vehicles go cross the bridge. 
The vibration equation of vehicle and bridge are as follows:

$m_{t} \frac{d^{2} y_{t}}{d t^{2}}+m_{b} \frac{d^{2} y_{b}}{d t^{2}}+c_{a}\left(\frac{d y_{t}}{d t}+\frac{d y_{w}}{d t}\right)+k_{a}\left(y_{t}+w\right)=0$,

$m_{b} \frac{d^{2} y_{b}}{d t^{2}}+c_{b}\left(\frac{d y_{b}}{d t}+\frac{d y_{t}}{d t}\right)+k_{b}\left(y_{b}-y_{t}\right)=0$.

Supposing $w(x, t)=\sum_{n} X_{n}(x) T_{n}(t)$ by using variable separation method. Using simple supported beam as boundary condition and presuming that $X_{n}(x)=\sin (n \pi x / l)$. According the orthogonality of principal mode, the vibration differential equation under loads is as follows:

$\dddot{T}_{n}(t)+w_{n}^{2} T_{n}=\frac{2\left(m_{t}+m_{b}\right) g}{m l} \sin \frac{\pi v t}{l}+$

$\ddot{T}_{n}(t)+\frac{2 m_{t}}{m l} \frac{d y_{t}}{d t^{2}} \sin \frac{n \pi v t}{l}+\frac{2 m_{b}}{m l} \frac{d^{2} y_{b}}{d t^{2}} \sin \frac{n \pi v t}{l}$

With the help of variable separation method, suppose $w(x, t)=\sum_{n} X_{n}(x) T_{n}(t)$.By simply-supported beams with boundary condition,let $X_{n}(x)=\sin (n \pi x / l)$, Again according to the principal mode of orthogonality,get the vibration differential equation of the bridge under the action of load as follows:

$\ddot{T}_{n}(t)+w_{n}^{2} T_{n}=\frac{2\left(m_{t}+m_{b}\right) g}{m l} \sin \frac{\pi v t}{l}+\frac{2 m_{t}}{m l} \frac{d y_{t}}{d t^{2}} \sin \frac{n \pi v t}{l}+\frac{2 m_{b}}{m l} \frac{d^{2} y_{b}}{d t^{2}} \sin \frac{n \pi v t}{l}$,

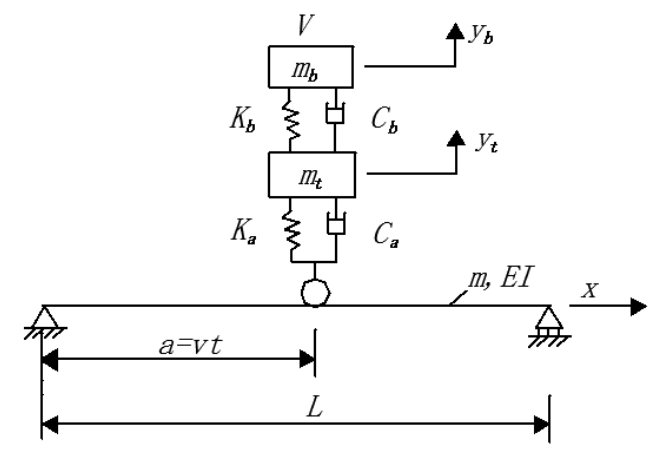

Fig. 1. One-fourth model under the effect of simply supported beam

Two quarter-car models will be used. The vibration equations for vehicle and bridge are taken into consideration separately, he the results are in superposition. The other one is the same.

\section{Half-car models}

Figure 2 is vehicle model, the spring-damper-mass system is for simulation of vehicles. Where $m_{b}$ is vehicle mass. $I_{b}$ is the rigidity of vehicle body; $m_{t}$ is the mass of wheels and structures; $k_{a}$ is vertical stiffness; $c_{a}$ is vertical damping; $k_{b}$ is vertical stiffness; $c_{b}$ is vertical damping; $v$ is the speed when vehicles go cross the bridge(constant value). The vibration equations are as follows ${ }^{[6]}$ : 
$\frac{d T_{n}(t)}{d t^{2}}+w_{n}^{2} T_{n}(t)=\frac{2 p_{1}(t)}{m l} \sin \frac{n \pi(v t-a)}{l} \delta_{1}(t)+\frac{2 \mathrm{p}_{2}(t)}{m l} \sin \frac{n \pi v t}{l} \delta_{2}(t)$

Which:

$\delta_{1}(t)=\left\{\begin{array}{cc}1, & \frac{a}{v} \leq t \leq \frac{l+a}{v} ; \\ 0, & \text { else },\end{array} \delta_{2}(t)=\left\{\begin{array}{cc}1, & 0 \leq t \leq \frac{l}{v} \\ 0, & \text { else }\end{array}\right.\right.$

Analysis of load of the vehicle system:

$$
\left.\begin{array}{l}
p_{1}(t)=m_{a 1} g+\frac{m_{b}}{2} g+m_{a 1} y_{t 1}+\frac{m_{s}}{2} y_{b}-\frac{I_{b}}{a} \ddot{\theta} \\
p_{2}(t)=m_{t 2} g+\frac{m_{b}}{2} g+m_{t 2} y_{t 2}+\frac{m_{b}}{2} y_{b}-\frac{I_{b}}{a} \theta
\end{array}\right\}
$$

Analysis of load of the bogie:

$$
\begin{array}{ll}
m_{t 1} \ddot{y}_{t 1}+c_{a 1}\left(\dot{y}_{t 1}+\dot{w}_{1}\right)+k_{a 1}\left(y_{t 1}+\mathrm{w}_{1}\right)+ & c_{b 1}\left(\dot{y}_{t 1}-\dot{y}_{b}+\frac{a}{2} \dot{\theta}\right)+k_{b 1}\left(y_{t 1}-y_{b}+\frac{a}{2} \theta\right)=0 \\
m_{t 2} \ddot{y}_{t 2}+c_{a 2}\left(\dot{y}_{t 2}+\dot{w}_{2}\right)+k_{a 2}\left(y_{t 2}+\mathrm{w}_{2}\right)+c_{b 2}\left(\dot{y}_{t 2}-\dot{y}_{b}-\frac{a}{2} \dot{\theta}\right)+k_{b 2}\left(y_{t 2}-y_{b}-\frac{a}{2} \theta\right)=0 & \text { Which: } \\
w_{1}=\sum_{n} X_{n}(v t-a) T_{n}(t) ; \quad w_{2}=\sum_{n} X_{n}(v t) T_{n}(t) &
\end{array}
$$

Analysis of load of the body:

$$
\begin{array}{lr}
m_{b} \ddot{y}_{b}+c_{b 1}\left(\dot{y}_{b}-\dot{y}_{t 1}-\frac{a}{2} \dot{\theta}\right)+k_{b 1}\left(y_{b}-y_{t 1}-\frac{a}{2} \theta\right)- & c_{b 2}\left(y_{t 2}-\dot{y}_{b}-\frac{a}{2} \dot{\theta}\right)-k_{b 2}\left(y_{t 2}-y_{b}-\frac{a}{2} \theta\right)=0 \\
I_{b} \ddot{\theta}-\frac{a}{2}\left[c_{b 1}\left(y_{b}-\dot{y}_{t 1}-\frac{a}{2} \dot{\theta}\right)+k_{b 1}\left(y_{b}-y_{t 1}-\frac{a}{2} \theta\right)\right]+\frac{a}{2}\left[c_{b 2}\left(\dot{y}_{b}-\dot{y}_{t 2}-\frac{a}{2} \dot{\theta}\right)+k_{b 2}\left(y_{b}-y_{t 2}-\frac{a}{2} \theta\right)\right]=0 .
\end{array}
$$

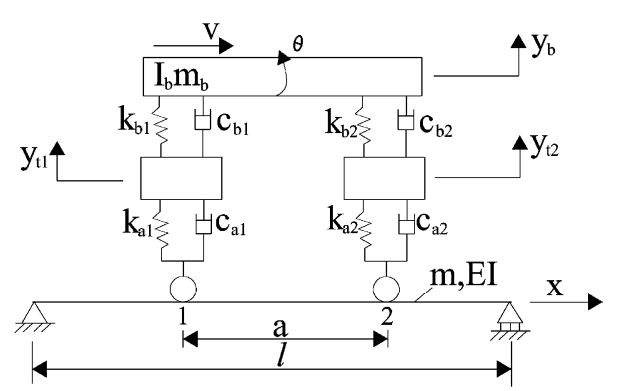

Fig. 2.Half-car model under the effect of simply supported beam

\section{Results}

Bridge data in document ${ }^{[11]}$ and vehicle data in document ${ }^{[12]}$ are used, the length of simple supported beam is $\mathrm{L}=32 \mathrm{~m}$. Mass per unit length $\mathrm{m}=5.41 \times 10^{3} \mathrm{~kg} / \mathrm{m}$. flexural rigidity $E I=3.5 \times 10^{10} \mathrm{~N} \bullet \mathrm{m}^{2}$. Following are relevant data of quarter-car model: $m_{t 1}=m_{t 2}=4330 \mathrm{~kg} ;$ $\mathrm{m}_{b}=19250 \mathrm{~kg} \quad ; \quad \mathrm{a}=8.4 \mathrm{~m} \quad ; \quad k_{a 1}=k_{a 2}=4.28 \times 10^{6} \mathrm{~N} / \mathrm{m} \quad ; \quad k_{b 1}=k_{b 2}=2.535 \times 10^{6} \mathrm{~N} / \mathrm{m} \quad ;$ $c_{a 1}=c_{a 2}=9.8 \times 10^{4} \mathrm{~kg} / \mathrm{s} ; c_{b 1}=c_{b 2}=1.96 \times 10^{5} \mathrm{~kg} / \mathrm{s} \circ 1 / 2$ car models $: c_{a 1}=c_{a 2}=9.8 \times 10^{4} \mathrm{~kg} / \mathrm{s} ;$ $\mathrm{m}_{b}=38500 \mathrm{~kg} \quad ; \quad m_{t 1}=m_{t 2}=4330 \mathrm{~kg} \quad ; \quad I_{b}=2.446 \times 10^{6} \mathrm{~kg} \bullet \mathrm{m}^{2} \quad ; \quad \mathrm{a}=8.4 \mathrm{~m} \quad ;$ 
$k_{a 1}=k_{a 2}=4.28 \times 10^{6} \mathrm{~N} / \mathrm{m} ; k_{b 1}=k_{b 2}=2.535 \times 10^{6} \mathrm{~N} / \mathrm{m} ; c_{b 1}=c_{b 2}=1.96 \times 10^{5} \mathrm{~kg} / \mathrm{s}$ 。

Figure $3 \sim$ Figure 6 compare 3 kinds of vehicles vertical displacement at mid-point of beam at same speed. Figure 7 shows the largest displacement of the 3 kinds of models on the bridge under different speed. The comparison of curves in the figure shows that the 3 kinds of models could embody coupling response.

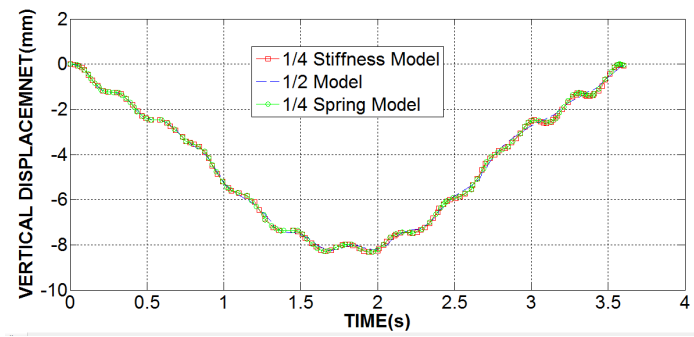

Fig. 3. Vertical displacement at mid-point of beam at speed $40 \mathrm{~km} / \mathrm{h}$

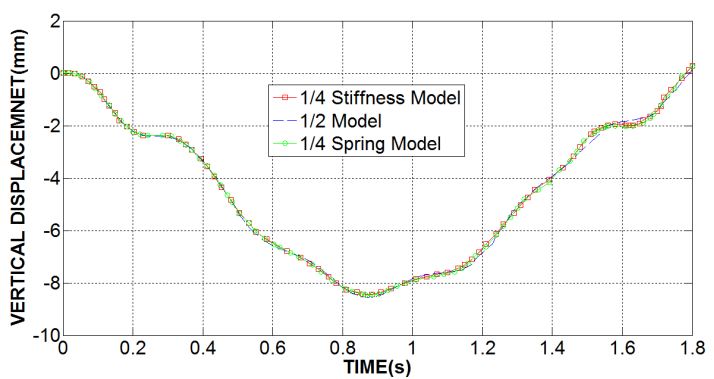

Fig. 4. Vertical displacement at mid-point of beam at speed $80 \mathrm{~km} / \mathrm{h}$

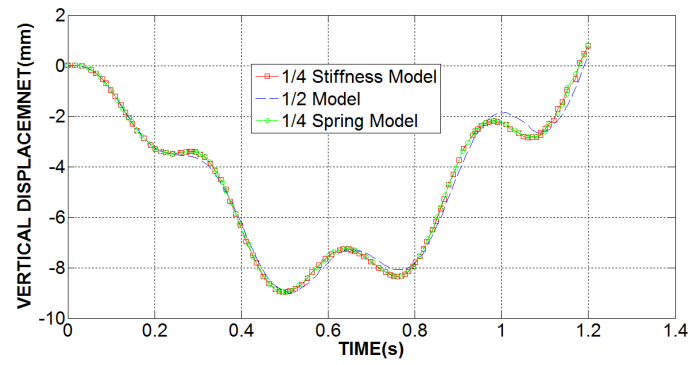

Fig. 5. Vertical displacement at mid-point of beam at speed $120 \mathrm{~km} / \mathrm{h}$

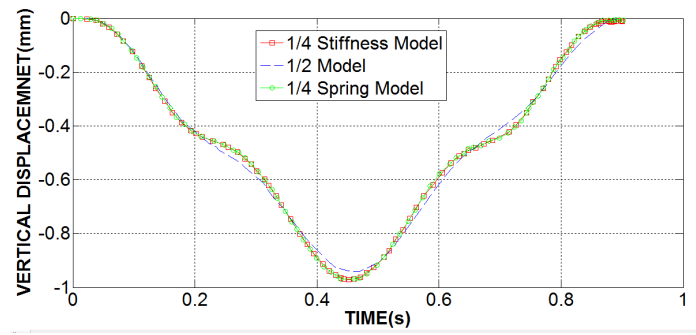

Fig. 6. Vertical displacement at mid-point of beam at speed $160 \mathrm{~km} / \mathrm{h}$

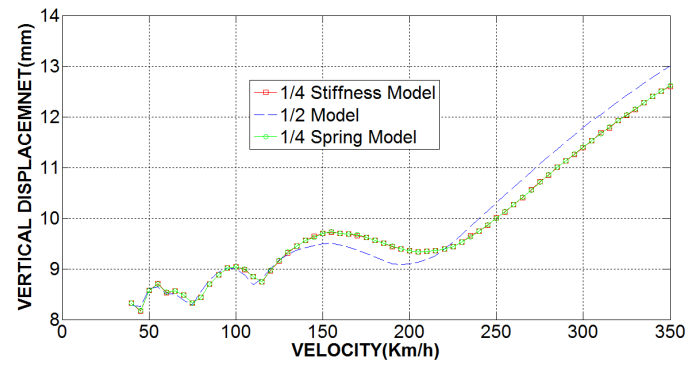

Fig. 7. The largest displacement on the bridge under different speed 
General laws could be arrived at based on above figures:

(1) They all give good expression to the vibration response.

(2) Higher speed will make a slower displacement response of mid-span.

(3) Response Maximum displacement in bridge when vehicle appear in mid-span.

(4) When speed is under $200 \mathrm{~km} / \mathrm{h}$, response of maximum displacement bridge do not take on a linear relationship.

The difference between vehicle models are as follows:

(1) The difference between $1 / 4$ spring model of rigidity and $1 / 4$ spring model is the change of rigidity. The displacement response in mid-span of bridge fits well with each other. Spring stiffness has no impact on vehicle-bridge coupling.

(2) When speed is under $130 \mathrm{~km} / \mathrm{h}$, the discrepancy of maximum displacement in $1 / 4$ vehicle model and $1 / 2$ vehicle model is small.

(3) When speed is under $220 \mathrm{~km} / \mathrm{h}$, the maximum displacement in $1 / 2$ vehicle model is smaller than that $1 / 2$ vehicle model. The vehicle-bridge coupling is more sensitive to moment of inertia.

(4) When speed is more than $220 \mathrm{~km} / \mathrm{h}$, the maximum displacement in $1 / 2$ vehicle model is greater than that $1 / 2$ vehicle model.

(5) Generally speaking, the vehicle speed is no more than $120 / \mathrm{h}$, The vehicle-bridge coupling can be realized using $1 / 4$ model in highway bridge.

\section{Conclusions}

To study the response of factor of vehicle model to the vehicle-bridge coupling, the displacement of mid-span of 3 kinds of models are caculated. Comparison shows that the 3 kinds of models are in good agreement with vibration response of vehicle-bridge coupling. With the add of rotational inertia, the agreement will be better yet make the analysis complicated. When velosity is under $130 \mathrm{~km} / \mathrm{h}$, the 3 kinds of models are in good agreement with each other. Quarter-car models can be used to analyse vibration of vehicle-bridge coupling in highway bridge.

\section{References:}

[1] MichaltsosG,Sophianopoulos D, KounadisA N. The effect of a moving mass and other parameters on the dynamic response of a simply supported beam[J]. Journal of Sound and Vibration, 1996; 191(3): 357-362.

[2] Cai Y, Chen S S, Rote D M, et al. Vehicle/guideway interraction for high speed vehicles on a flexible guideway[ J]. Journal of sound and Vibration, 1994; 175(5): 625-646.

[3] Ma Kunqun, Cao Xueqin. Train lateral vibration analysis of through continuous beam bridge with high Pier [J]. Shanghai: Shanghai tiedao University, 1993,15 (1): 9-15.

[4] Wang Yuanfeng, Xu Shijie. Study on dynamic response of bridge under the vehicle space [J]. China Journal of highway and transport. 2000,13 (4): 38-41.

[5] Xiaoxinbiao, Shen Huoming. Bridge simulation System under moving load[J]. Vibration and impact, 2005,24 (1): 121-123.

[6] Shen Huoming, xiaoxinbiao. Solution of a numerical method for vehicle-bridge coupling vibration[J]. Journal of Southwest Jiaotong University, 2003,38 (6): 658-662.

[7] Peng Xian, Yin Xinfeng, Fang Zhi.Variable speed vehicle-bridge coupling vibration and TMD control [J]. Journal of Hunan University(Natural Sciences), 2006,26 (5): 19-21,37.

[8] Stokes G G.Discussions of a differential equation related tothe breaking of railway bridges[ J].Trans Cambridge PhilSoc, 1896,8:12- 16. 
[9] Kolousek V,Flyba L.Civil engineering structures subjectedto dynamic load[M].Bratislava:SVTL, 1967:54- 58.

[10] Andersen L,Nielsen S R K,Iwankiewicz R.Vehicle movingalong an infinite beam with random surface irregularities on a Kelvin foundation[J]. Journal of Applied Mechanics,2002:69- 75.

[11] Xue Ding-Yu, Chen Yangquan. MATLAB/Simulink-based simulation technology and application[M]. Beijing: Tsinghua University Press, 2002:180-200.

[12] Zhai Wanming. Vehicle-track coupling Dynamics[M]. Beijing: China railway Publishing House, 2001:360-370. 